\title{
Malignant melanoma as a target malignancy for the study of the anti-metastatic properties of the heparins
}

\author{
Anthony Maraveyas • Miriam J. Johnson • \\ Yu Pei Xiao • Simon Noble
}

Published online: 9 October 2010

(C) The Author(s) 2010. This article is published with open access at Springerlink.com

\begin{abstract}
The outlook for metastatic melanoma to the brain is dismal. New therapeutic avenues are therefore needed. The anti-metastatic mechanisms that may underpin the effects of low molecular weight heparins (LMWHs) in in vitro and preclinical melanoma models warrant translating to a clinical setting. This review outlines a rationale that supports our proposal that metastatic melanoma to the brain is a clinical setting in which to study the anti-metastatic potential of LMWHs. Prevention or delay of brain metastases in melanoma is a clinically relevant and measurable target. Studies to explore the effect of anticoagulants on cancer survival are underway in other malignancies such as lung, pancreas, ovary, breast, and stomach cancer. However, no study to our knowledge has a methodology that could produce clinical evidence in support of a mechanism for whatever benefit may be seen. The setting we propose would allow translation of the molecular knowledge of the metastatic pathways mediated by platelets and the selectins - all potential targets of
\end{abstract}

A. Maraveyas · M. J. Johnson · Y. Xiao

Hull York Medical School, University of Hull,

Hull HU6 7RX, UK

\author{
A. Maraveyas $(\bowtie)$ \\ Queen's Centre for Oncology and Hematology, \\ Castle Hill Hospital, \\ Hull HU16 5JQ, UK \\ e-mail: anthony.maraveyas@hey.nhs.uk \\ M. J. Johnson \\ St. Catherine's Hospice Scarborough, \\ Scarborough YO11 2QF, UK \\ S. Noble \\ Cardiff University School of Medicine, \\ Heath Park, \\ Cardiff CF14 4XN, UK
}

heparin - in a "time to appearance" of brain metastases endpoint. Since brain metastases are so common and they have a singularly adverse impact on survival, the "biological neuroprotection" model we propose in metastatic melanoma could provide the translational evidence to support the benefit of LMWHs in melanoma. More significantly, this would open the door to a wider "antimetastatic" approach that could have much greater impact in patients with minimal disease being treated in adjuvant settings for the more common malignancies such as breast and colon cancer.

Keywords Low molecular weight heparins · Metastatic melanoma $\cdot$ Selectin $\cdot$ Anti-metastatic

\section{Introduction}

The benefits from using anticoagulants in the treatment of patients with cancer may arise from two clinically different but biologically intertwined routes: direct effects (treatment or prevention) on thrombotic complications of malignancy and postulated anti-metastatic cancer effects.

From early laboratory and preclinical studies, melanoma may be a malignancy that would benefit from anticoagulant agents. Unlike pancreatic cancer [1], melanoma is not highly thrombogenic, and the clinical benefit suggested is unlikely to be solely due to the prevention of venous thromboembolism [2]. Preclinical experiments in the 1980s of anticoagulants in cancer treatment led to some poorly designed underpowered clinical trials which suggested improved survival in small cell lung cancer (SCLC) and melanoma. These two malignancies have three things in common: a relatively low incidence of thrombosis $[2,3]$, neuroectodermal origin, and early metastasis, often to the 
brain. These two malignancies, however, are very different in terms of sensitivity to conventional treatments. The exquisite radiosensitivity of SCLC has led to survival gains through the neuroprotective strategy of prophylactic cranial irradiation [4] whereas melanoma is relatively radioresistant. However, if a method of neuroprotection can be found for melanoma, similar survival benefits to those in SCLC may result.

These almost unique clinical properties of malignant melanoma - a tendency for indiscriminate and multiple metastases and lethal consequences of brain metastases, coupled to the lack of confounding parameters of thrombophilia or a neuroprotective strategy - suggest melanoma as a model malignancy to study the anti-metastatic potential of low molecular weight heparins (LMWHs). This paper outlines the rationale supporting this proposal.

\section{Brain metastases in melanoma}

The high mortality in melanoma patients relates to the high incidence of brain metastases; the median survival of unselected melanoma patients with brain metastases is only 2-4 months [5]. Melanoma cells appear to have substantial neurotropism; it is the fourth most common primary site to metastasize to the brain [6]. Melanoma accounts for $10 \%$ of all brain metastases and has the second highest incident proportion percentage [7]; up to $13 \%$ of patients with regional disease (AJCC stage III) [8], 18-46\% of stage IV patients $[6,8]$, with a prevalence of up to $75 \%$ at autopsy [8-11].

It was hoped that two cytotoxic agents that cross the blood-brain barrier (BBB) (temozolomide and/or fotemustine) would improve survival. Unfortunately, neither drug provided any statistical advantage compared with the current gold standard, dacarbazine (DTIC) [12, 13]. This probably reflects the poor overall chemosensitivity of melanoma, although fotemustine [12] did fare somewhat better than dacarbazine in demonstrating a delay in the onset of brain metastases; the median time to brain metastases was 22.7 months $(95 \%$ confidence interval (CI), 9.62-23.33) in the fotemustine arm versus 7.2 months $(95 \% \mathrm{CI}, 6.28-11.70)$ in the DTIC arm $(P=.059)$. This just failed to translate into an overall survival advantage; 7.3 months (95\% CI, 6.01-8.84) in the fotemustine arm versus 5.6 months (95\% CI, 5.03-6.54) in the DTIC arm ( $P=.067$ in the intent-to-treat population) which may reflect an underpowered study. Nevertheless, it strongly suggests that a survival benefit could accompany better CNS control of melanoma metastases and that a strategy of "biological interference" with the metastatic process to the brain may result in survival benefit for patients with advanced melanoma.

\section{Elements of neuroprotective strategies}

The data from the above mentioned phase III trial [12] show that $20 \%$ of patients had brain metastases at study entry and $20 \%$ developed them over the assessment period of around 6 months. It is unlikely that all the brain metastases that develop post-randomization result from pre-implanted melanoma cells. It is more likely that a proportion of these have resulted from an ongoing process of melanoma cells shed from other metastases continuously arriving in the microcirculation of the brain - slowing down, attaching to endothelium, and finally, successfully implanting.

A neuroprotection model of "biological interference" would assume that BBB invasion by melanoma cells is a stochastic event, i.e., occurs randomly on a background of a predictable continuous process, thus requiring continuous prophylaxis. This model can be broken down into three components:

(1) Cytoreduction-i.e., reducing the burden of BBB implanted cells.

(2) Inactivation of the "metastatic niche"-i.e., interfering with the mechanisms driving invasion.

(3) Prevent implantation - i.e., interfering with the process of endothelial cellular attachment.

This model differs to that of SCLC mostly because the conventional modalities of chemotherapy and radiotherapy achieve all the above stated components through the exquisite sensitivity of SCLC to these treatments. Thus, cytoreduction and inactivation are achieved by the chemotherapy and the radiotherapy while further implantation is reduced by the systemic response to chemotherapy; the efficacy of this strategy is mostly seen in patients who have achieved complete or consolidated partial response with radiotherapy [4].

In melanoma, this is not possible as we have no agents that can deliver this "neuroprotective" component through significant cancer cell kill. However, if a strategy of continual "inactivation" and "interference" with the metastatic process can be developed to complement a cytotoxic induction phase, however modest, one may produce a survival benefit.

\section{Coagulation pathways and the metastatic process}

Cancer cells are continuously shed into the circulation either from the primary or from established metastases. However, the metastatic process is inefficient and cell survival in the circulation is low due to a combination of shear forces, phagocytosis, and obstruction within capillary beds. Only $1.5 \%$ of nonhematogenous cells injected into the bloodstream survive for more than $24 \mathrm{~h}$ [14]. 
The complex biological pathways of the metastatic process can, simplistically, be categorized as coagulationdependent and coagulation-independent. These insights have existed for more than 30 years [15]. Although there is some evidence that some of the coagulation factors may also be involved in coagulation-independent promotion of metastasis (such as tissue factor [16]), it appears that the successful negotiation of the intravascular phase of the cancer cell journey is heavily dependent on mechanical and signaling interactions that would promote thrombosis in the physiological state. There is unequivocal evidence of the interactions between disseminating tumor cells and blood cells, mainly platelets [17-19]. Initial support for an active role of platelets in metastasis was obtained from a mouse model in which experimental thrombocytopenia led to attenuation of metastasis [19]. The significance of the tumor cell microemboli formation was suggested when the intravenous injection of tumor cells led to a rapid association with platelets, whereas in the absence of this interaction, tumor cells were cleared by natural killer (NK) cells [20]. The intravenous tumor cell injection coincided with a temporal reduction of peripheral platelet counts. Interference with platelet-tumor cell interactions resulted in the attenuation of metastasis, further supporting the protective role of microemboli formation for tumor cell survival [21,22]. These "transit" metastatic emboli include leucocytes and function as vehicles that shield the cancer cell(s) from shear forces and immunosurveillance (NK cells) [23], maintain viability of the cancer cell(s) through signaling [24, 25], promote retention in capillaries, and provide an in situ readily available repository of signaling molecules that facilitate colonization of distant organs [26, 27] when the microembolic phase is initiated. Propagationprolongation of this process through maintenance of the micro thrombosis-related microenvironment (activation of cytokines and coagulation factors) promote establishment of the "metastatic niche" (Fig. 1).

\subsection{Coagulation factors and melanoma metastases}

Coagulation factors, particularly thrombin and tissue factor (TF), play an important role in melanoma metastasis [2831]. Thrombin stimulates platelets, induces tumor angiogenesis, regulates tumor cell adhesion to platelets and endothelial cells, and promotes tumor growth and metastasis [28-30]. Thrombin responses in melanoma cell motility and metastasis depend on proteinase-activated receptor-1 (PAR1) [32]; PAR1 is also required in the development of TF-mediated metastasis [33]. The PAR1 expression is significantly higher in metastatic melanoma cells, which however have undetectable levels of endogenous activator protein 2 (AP-2) [30, 32]. The loss of transcription factor AP-2 is a crucial event in the development of malignant melanoma [34] and results in overexpression of PAR1 that regulates the metastatic phenotype of melanoma [35] by induction of cell adhesion molecules, matrix-degrading proteases, stimulating the secretion of angiogenic and invasive factors [30, 36-38]. PAR1 and thrombin could be potential targets for antitumor and anti-metastasis therapy for melanoma patients [30, 35, 37]. The data contribute to a mechanistic explanation of the preclinical data that have persistently pointed to potential anti-metastatic properties of anticoagulants [30, 39] via effects on the coagulation cascade.

\section{Endothelial accesses and the metastatic process}

The arrest of cancer cells in small vessels is an important step in metastasis. Although simple mechanical entrapment has been proposed [40, 41], more complex processes are involved [26, 39, 42-44] including the alteration of cell surface glycosylation, which is a common feature of carcinoma progression and metastasis; in particular, high expression of sialylated fucosylated glycans such as sialyl Lewisx/a. A further significant role in these processes is played by integrins [45] and although very recently, antimetastatic effects of heparins in melanoma have been postulated to be mediated in certain cases though interaction of heparin with integrins [46, 47], the complexity, diversity, and the non-uniform impact of heparins [48] on this pathway put a detailed discussion beyond the scope of this review.

\subsection{Selectins and cell "docking"}

Selectins are a family of mammalian vascular adhesion molecules: $\mathrm{P}$ (latelet)-selectin, $\mathrm{E}$ (ndothelial)-selectin, and $\mathrm{L}$ (eucocyte)-selectin [49]. Both E- and P-selectins are inducible membrane proteins expressed on activated endothelial cells or platelets following various proinflammatory cytokine stimulations such as TNF and thrombin [50]. Selectins could interact with those sialyl Lewisx/a-containing cell surface glycoconjugates, normally found on mucintype glycoproteins of leukocytes and endothelium, and mediate tethering, rolling, and adhesion of cells [49, 51, 52]. Thus, "deceleration" to achieve surface purchase is achieved through cellular glycocalyx and selectin-mediated interactions inducing "rolling", in a manner that is similar to that in the regulated recruitment of leukocytes to tissue sites of damage and inflammation.

P-selectin has been demonstrated to mediate crucial cancer cell interactions with platelets and endothelial cells $[39,49,51,53]$. The expression of E- and P-selectin on endothelial cells initiates tethering and rolling of the cancer cells and formation of weak adhesions to the endothelial cells within the capillary bed [21]. Rolling is now thought 
Fig. 1 Potential role of heparin-selectin interaction in melanoma metastasis. a Platelettumor cell microemboli formations are primarily mediated by $\mathrm{P}$-selectin and platelet aggregation. L-selectin mediates the recruitment of leukocytes to tumor cells. These "transit" metastatic emboli include leucocytes and function as vehicles that shield the tumor cell from shear force and immunosurveillance (NK cells). The expression of E- and P-selectin on endothelial cells initiates tethering and rolling of tumor cells. This weak adhesion to the endothelium promotes establishment of the "metastatic niche" usually associated with more "definitive" binding to intercellular cell adhesion molecules. b Heparins bind to selectins and inhibit their function
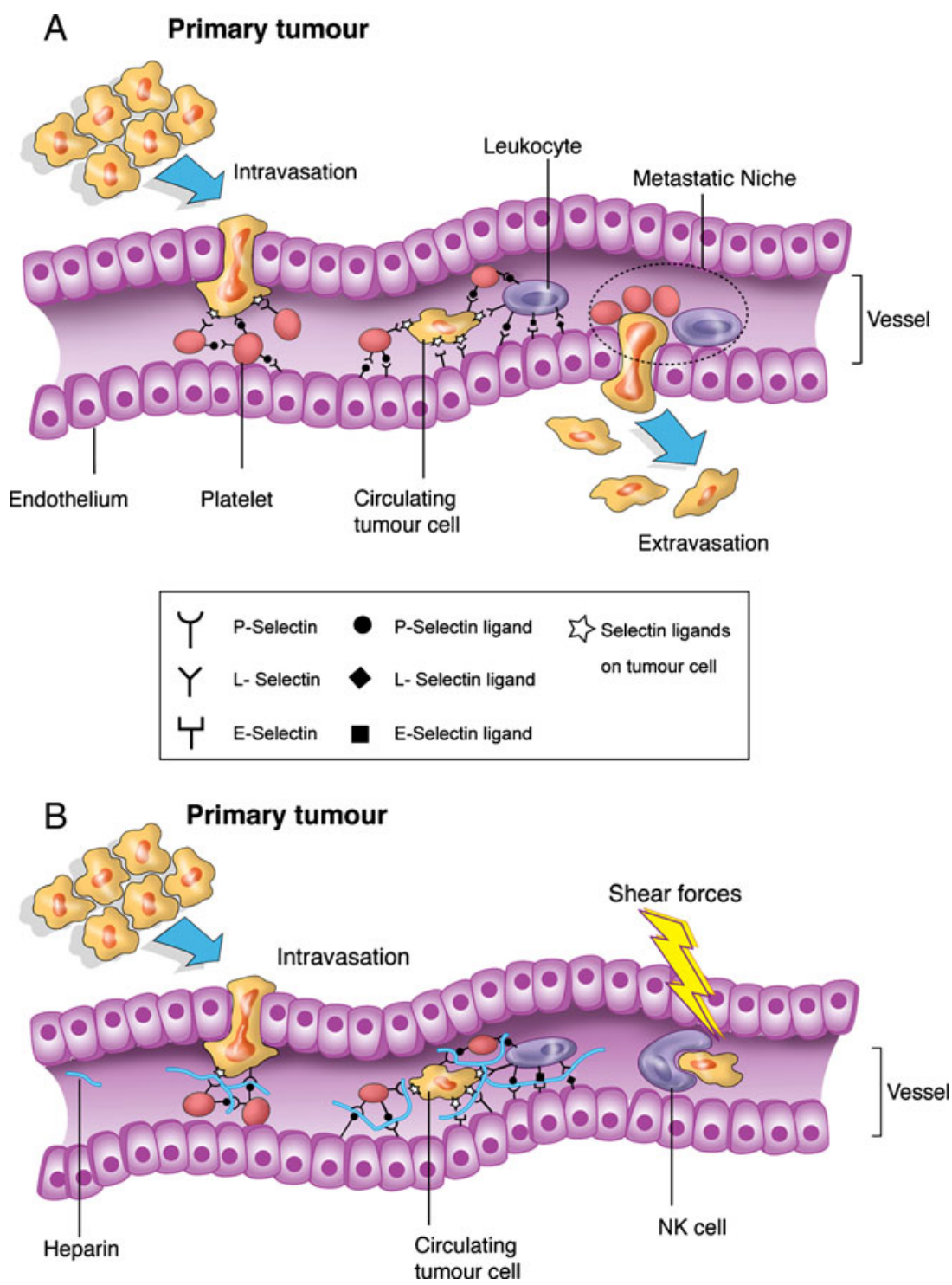

to be a major primary deceleration mechanism used by melanoma cells prior to more definitive integrin-related anchoring to the endothelium [54].

\section{Heparins and melanoma metastases}

\subsection{The in vitro and preclinical evidence}

The effect of the heparins on the melanoma metastatic process has been repeatedly demonstrated since in both experimental and spontaneous metastatic models (Table 1). The emergence of the role of selectins regulating this "docking" process of the cancer cell has pinpointed that at least in the experimental tumor cell models the total effect of heparin on the platelet-tumor cloak can be accounted for by its interactions with P-selectin molecules [39, 55]. Moreover, these investigators and others [54, 56] have demonstrated that the interactions of the cancer cell with Pand E-selectins on endothelium are equally important for adhesion and similarly a major therapeutic target of the heparins [55, 57] (Fig. 1).

6.2 The proposed mechanism of the heparin-selectin interaction

P-selectin binds a large range of heparin sulfate and heparin fragments [57]. L-selectin may require a more specific sequence for recognition. Although binding to Sialyl-Lewis $\mathrm{X}$ motif on mucin-like molecules is thought to be a shared ligand between the selectins, this interaction is weak [42, 58], and there is no clear superior single structural motif. The suggested mechanism is that the recognition involves a "clustered anionic patch", rather than a linear-defined oligosaccharide sequence. The most convincing high affinity interaction discovered is that of P-selectin glyco- 
Table 1 Preclinical and in vitro evidence of molecular targets of heparins in malignant melanoma

\begin{tabular}{|c|c|c|c|}
\hline $\begin{array}{l}\text { Molecular } \\
\text { target }\end{array}$ & Model & Type of Heparin & Mechanisms \\
\hline $\begin{array}{r}\text { Endothelial } \\
\text { P-selectin }\end{array}$ & $\begin{array}{l}\text { B16F10 injected mice; murine B16F10, } \\
\text { human NW624 and NW1539 cells }\end{array}$ & UFH & $\begin{array}{l}\text { Heparin not only inhibits endothelial P- } \\
\text { selectin-mediated melanoma cell rolling } \\
\text { on microvasculature, but also attenuates } \\
\text { melanoma metastasis formation in vivo } \\
\text { [61]. }\end{array}$ \\
\hline P-selectin & Human A375 cells & Modified heparin & $\begin{array}{l}\text { Heparin can block P-selectin-mediated } \\
\text { A375 human melanoma cell adhesion } \\
{[67,68] .}\end{array}$ \\
\hline P-selectin & $\begin{array}{l}\text { B16 injected mice; murine B16, } \\
\text { human NW624 and NW1539 cells }\end{array}$ & $\begin{array}{l}\text { UFH; LMWHs (nadroparin, enoxaparin); } \\
\text { synthetic pentasaccharide fondaparinux }\end{array}$ & $\begin{array}{l}\text { UFH and LMWHs inhibit P-selectin me- } \\
\text { diated rolling of melanoma cells in vitro } \\
\text { and in vivo [56]. }\end{array}$ \\
\hline P-selectin & $\begin{array}{l}\text { B16-BL6 injected mice; } \\
\text { murine B16-BL6 cell }\end{array}$ & Heparin derivatives & $\begin{array}{l}\text { Modified non-anticoagulant species of } \\
\text { heparin specifically inhibit selectin- } \\
\text { mediated cell-cell interactions, hepara- } \\
\text { nase enzymatic activity, or both [69]. }\end{array}$ \\
\hline Selectins & $\begin{array}{l}\text { B16F10 injected mice; } \\
\text { murine B16F10 cell }\end{array}$ & $\begin{array}{l}\text { Orally absorbable heparin derivative } \\
\text { (LHD) }\end{array}$ & $\begin{array}{l}\text { Orally active LHD could have anti- } \\
\text { metastatic effect via inhibition of cell- } \\
\text { cell interaction between melanoma cells } \\
\text { and platelets or HUVECs by interrupt- } \\
\text { ing selectin-mediated interactions [54]. }\end{array}$ \\
\hline $\begin{array}{l}\text { Integrin } \\
\alpha 4 \beta 1 \\
\text { (VLA-4) }\end{array}$ & Murine B16F10, human MV3 cells & $\begin{array}{l}\text { UFH; LMWH (tinzaparin), } \\
\text { a fraction of tinzaparin, fondaparinux. }\end{array}$ & $\begin{array}{l}\text { Heparin is shown to interfere with the } \\
\text { VLA-4/VCAM-1 interaction and inhibit } \\
\text { integrin VLA-4-mediated interactions } \\
{[46,70] \text {. }}\end{array}$ \\
\hline $\begin{array}{l}\text { Integrin } \\
\qquad \alpha \operatorname{IIb} \beta 3\end{array}$ & $\begin{array}{l}\text { B16F10 or A375 injected mice; } \\
\text { murine B16F10 and Human A375 cells }\end{array}$ & Modified heparins & $\begin{array}{l}\text { Modified heparins can inhibit melanoma } \\
\text { tumor cell-platelet interaction mediated } \\
\text { by platelet integrin } \alpha \operatorname{IIb} \beta 3 \text { [47]. }\end{array}$ \\
\hline $\begin{array}{l}\text { PAR1and } \\
\text { CD24 }\end{array}$ & $\begin{array}{l}\text { B16 and K1735 injected mice; } \\
\text { murine B16 and K1735 cells }\end{array}$ & LMWH (nadroparin) & $\begin{array}{l}\text { LMWH inhibits thrombin-dependent } \\
\text { PAR1 activation, thus, further inhibiting } \\
\text { the platelet or endothelial cell activation } \\
\text { and L- and P-selectin-mediated cell-cell } \\
\text { adhesion; cancer cell express CD24 } \\
\text { takes part in metastasis as a ligand of P- } \\
\text { selectin. LMWH inhibits P-selectin/ } \\
\text { CD24 interaction prevent binding of } \\
\text { platelets to cancer cells [71]. }\end{array}$ \\
\hline
\end{tabular}

UFH unfractionated sodium heparin, $L M W H s$ low molecular weight heparins

protein ligand-1 (PSGL-1) with P-selectin. This sialomucin polypeptide is expressed on all leucocytes but becomes specialized for selectin recognition on neutrophils and monocytes. The most interesting biophysical aspect of interaction of these molecules is that it involves novel "catch bonds" which help to explain the rollin g behavior shown by leucocytes coming into contact with endothelium [59,60].

Unrelated glycans (e.g., the heparins) can also act as ligands for L- and P-selectins and the clinically used molecules (highly sulfated) are potent inhibitors, causing complete inhibition of both L- and P-selectins in vitro assay within recommended clinical anticoagulation target levels, with unfractionated heparin being the most potent (Fig. 1). Ludwig et al. [56, 61], employing the murine B16 melanoma lung metastasis model, revealed that heparin treatment inhibited lung colonization (by $>80 \%$ ) if given prior to, but not after intravenous inoculation of melanoma cells. They showed that heparin inhibits melanoma rolling in a P-selectin-dependent fashion. Whereas in P- selectin ${ }^{-/}$ mice rolling remained unaffected by heparin, in wild-type mice heparin treatment reduced rolling of three different melanoma cell lines (Mel1539, Mel624, and B16F10) in a dose-dependent manner. Together, these data support the assumption that both platelet and endothelial P-selectin are potential targets of heparin action in melanoma metastasis formation. These effects have been reproduced using an orally administered heparin (a chemical conjugate of LMWH and deoxycholic acid) in a murine melanoma lung metastases model [54]. The LMWHs have similar effects but $\mathrm{IC}_{50}$ values of these compounds against selectin-PSGL-1 
interactions were closer to the recommended target range for therapeutic anticoagulation. This difference between unfractionated and LMW heparins is likely to be due to the reduced efficacy of smaller-sized fragments interacting with the "clustered anionic patch". Nevertheless, even these agents, dosed at therapeutic (rather than prophylactic) levels, are highly effective selectin inhibitors [56, 61].

\subsection{The clinical evidence}

There has been a recent resurgence in the interest of the potential effect of anticoagulants in cancer. Unfortunately, the studies reported to date $[62,63]$, although hinting at potential survival benefits from the use of LMWH, are difficult to interpret as the populations studied are usually mixed in terms of histology type and stage of cancer. It is difficult to determine whether the effect is through prevention of thrombosis (e.g., in mucin-producing adenocarcinomas) or through potential non-anticoagulantmediated anti-malignancy effects. Therefore, it is interesting to consider the historical studies which, while smaller and less robust, focused on specific cancers.

At least two studies in SCLC demonstrated a survival benefit for those receiving unfractionated sodium heparin (UFH) or LMWH $[3,64]$. The thrombosis incidence in the control groups was negligible but the benefit was significant. This was difficult to explain and although it was attributed to a better response rate at least in one study, we suggest that other mechanisms relating to modification of the natural history of this disease (such as reducing incidence or delaying onset of brain metastases) may have played a role. There are no data from these trials to support or refute this hypothesis.

The data suggesting clinical role and effect of anticoagulants on melanoma have been previously summarized $[65,66]$. All the studies reviewed pointed to survival benefit with anticoagulants although warfarin was the only anticoagulant used in these early studies. Mechanisms suggested were those of thrombin inhibition and possibly beneficial effects on TF generation.

We therefore suggest that heparin or LMWH strategies employed for their capacity to interfere with the metastatic process have reasonable data in support and that the model of prevention or delay of melanoma brain metastases could be one that could elicit this benefit in a clinically measurable sense (brain metastases-free interval) that could also result in a patient relevant benefit in terms of survival.

\section{Summary}

The anti-metastatic mechanisms that may underpin the effects of heparin-LMWH in in vitro and preclinical melanoma models warrant testing in the clinical setting as prevention or delay of brain metastases in melanoma appears to be a clinically relevant and measurable target. Studies to explore the effect of anticoagulants on cancer survival are underway in other malignancies such as lung, pancreas, ovary, breast, and stomach cancer. However, no study to our knowledge has a methodology that could produce clinical evidence in support of a mechanism for whatever benefit may be seen. The "biological neuroprotection" model we propose in metastatic melanoma could provide this evidence, supporting the benefit of LMWH in melanoma, but more significantly, opening the door to a wider "anti-metastatic" approach that could have much greater impact in patients with minimal disease being treated in adjuvant settings for the more common malignancies such as breast and colon cancer.

Acknowledgments The authors wish to thank Jan Sharp for the technical support with the photographic images.

Open Access This article is distributed under the terms of the Creative Commons Attribution Noncommercial License which permits any noncommercial use, distribution, and reproduction in any medium, provided the original author(s) and source are credited.

\section{References}

1. Sgouros, J., \& Maraveyas, A. (2008). Excess premature (3-month) mortality in advanced pancreatic cancer could be related to fatal vascular thromboembolic events. A hypothesis based on a systematic review of phase III chemotherapy studies in advanced pancreatic cancer. Acta Oncológica, 47(3), 337-346.

2. Chew, H. K., Wun, T., Harvey, D., Zhou, H., \& White, R. H. (2006). Incidence of venous thromboembolism and its effect on survival among patients with common cancers. Archives of Internal Medicine, 166(4), 458-464.

3. Altinbas, M., Coskun, H. S., Er, O., Ozkan, M., Eser, B., Unal, A., et al. (2004). A randomized clinical trial of combination chemotherapy with and without low-molecular-weight heparin in small cell lung cancer. Journal of Thrombosis and Haemostasis, 2 (8), 1266-1271.

4. Slotman, B., Faivre-Finn, C., Kramer, G., Rankin, E., Snee, M., Hatton, M., et al. (2007). Prophylactic cranial irradiation in extensive small-cell lung cancer. The New England Journal of Medicine, 357(7), 664-672.

5. Douglas, J. G., \& Margolin, K. (2002). The treatment of brain metastases from malignant melanoma. Seminars in Oncology, 29 (5), 518-524.

6. Wen, P. Y., Black, P. M., \& Joeffler, S. L. (2001). Treatment of metastatic cancer. In V. T. Devita, S. Hellman, \& S. A. Rosenberg (Eds.), Cancer: principles and practice of oncology (6th ed., pp. 2655-2670). Philadelphia: Lippincott, Williams \& Wilkins.

7. Barnholtz-Sloan, J. S., Sloan, A. E., Davis, F. G., Vigneau, F. D., Lai, P., \& Sawaya, R. E. (2004). Incidence proportions of brain metastases in patients diagnosed (1973-2001) in the Metropolitan Detroit Cancer Surveillance System. Journal of Clinical Oncology, 22(14), 2865-2872.

8. Amer, M. H., Al-Sarraf, M., Baker, L. H., \& Vaitkevicius, V. K. (1978). Malignant melanoma and central nervous system metas- 
tases: incidence, diagnosis, treatment and survival. Cancer, 42(2), 660-668.

9. Budman, D. R., Camacho, E., \& Wittes, R. E. (1978). The current causes of death in patients with malignant melanoma. European Journal of Cancer, 14(4), 327-330.

10. Bullard, D. E., Cox, E. B., \& Seigler, H. F. (1981). Central nervous system metastases in malignant melanoma. Neurosurgery, 8(1), 26-30.

11. Patel, J. K., Didolkar, M. S., Pickren, J. W., \& Moore, R. H. (1978). Metastatic pattern of malignant melanoma. A study of 216 autopsy cases. American Journal of Surgery, 135(6), 807-810.

12. Avril, M. F., Aamdal, S., Grob, J. J., Hauschild, A., Mohr, P., Bonerandi, J. J., et al. (2004). Fotemustine compared with dacarbazine in patients with disseminated malignant melanoma: a phase III study. Journal of Clinical Oncology, 22(6), 1118-1125.

13. Middleton, M. R., Grob, J. J., Aaronson, N., Fierlbeck, G., Tilgen, W., Seiter, S., et al. (2000). Randomized phase III study of temozolomide versus dacarbazine in the treatment of patients with advanced metastatic malignant melanoma. Journal of Clinical Oncology, 18(1), 158-166.

14. Partridge, M. A., \& Marcantonio, E. E. (2006). Initiation of attachment and generation of mature focal adhesions by integrincontaining filopodia in cell spreading. Molecular Biology of the Cell, 17(10), 4237-4248.

15. Fidler, I. J. (1970). Metastasis: quantitative analysis of distribution and fate of tumor emboli labeled with 125i-5-iodo-2'- deoxyuridine. Journal of the National Cancer Institute, 45(4), 773-782.

16. Bromberg, M. E., Konigsberg, W. H., Madison, J. F., Pawashe, A., \& Garen, A. (1995). Tissue factor promotes melanoma metastasis by a pathway independent of blood coagulation. Proceedings of the National Academy of Sciences of the United States of America, 92(18), 8205-8209.

17. Honn, K. V., Tang, D. G., \& Crissman, J. D. (1992). Platelets and cancer metastasis: a causal relationship? Cancer and Metastasis Reviews, 11(3-4), 325-351.

18. Gasic, G. J. (1984). Role of plasma, platelets, and endothelial cells in tumor metastasis. Cancer and Metastasis Reviews, 3(2), 99-114.

19. Karpatkin, S., \& Pearlstein, E. (1981). Role of platelets in tumor cell metastases. Annals of Internal Medicine, 95(5), 636-641.

20. Palumbo, J. S., Talmage, K. E., Massari, J. V., La Jeunesse, C. M., Flick, M. J., Kombrinck, K. W., et al. (2005). Platelets and fibrin (ogen) increase metastatic potential by impeding natural killer cell-mediated elimination of tumor cells. Blood, 105(1), 178-185.

21. Nash, G. F., Turner, L. F., Scully, M. F., \& Kakkar, A. K. (2002). Platelets and cancer. The Lancet Oncology, 3(7), 425-430.

22. Jurasz, P., Alonso-Escolano, D., \& Radomski, M. W. (2004). Platelet-cancer interactions: mechanisms and pharmacology of tumour cell-induced platelet aggregation. British Journal of Pharmacology, 143(7), 819-826.

23. Nieswandt, B., Hafner, M., Echtenacher, B., \& Mannel, D. N. (1999). Lysis of tumor cells by natural killer cells in mice is impeded by platelets. Cancer Research, 59(6), 1295-1300.

24. Varon, D., \& Brill, A. (2001). Platelets cross-talk with tumor cells. Haemostasis, 31(Suppl 1), 64-66.

25. Baj-Krzyworzeka, M., Majka, M., Pratico, D., Ratajczak, J., Vilaire, G., Kijowski, J., et al. (2002). Platelet-derived microparticles stimulate proliferation, survival, adhesion, and chemotaxis of hematopoietic cells. Experimental Hematology, 30(5), 450-459.

26. Varki, N. M., \& Varki, A. (2002). Heparin inhibition of selectinmediated interactions during the hematogenous phase of carcinoma metastasis: rationale for clinical studies in humans. Seminars in Thrombosis and Hemostasis, 28(1), 53-66.

27. Browder, T., Folkman, J., \& Pirie-Shepherd, S. (2000). The hemostatic system as a regulator of angiogenesis. The Journal of Biological Chemistry, 275(3), 1521-1524.
28. Fischer, E. G., Ruf, W., \& Mueller, B. M. (1995). Tissue factorinitiated thrombin generation activates the signaling thrombin receptor on malignant melanoma cells. Cancer Research, 55(8), 1629-1632.

29. Melnikova, V. O., Villares, G. J., \& Bar-Eli, M. (2008). Emerging roles of PAR-1 and PAFR in melanoma metastasis. Cancer Microenvironment, 1(1), 103-111.

30. Tellez, C., \& Bar-Eli, M. (2003). Role and regulation of the thrombin receptor (PAR-1) in human melanoma. Oncogene, 22 (20), 3130-3137.

31. Mueller, B. M., Reisfeld, R. A., Edgington, T. S., \& Ruf, W. (1992). Expression of tissue factor by melanoma cells promotes efficient hematogenous metastasis. Proceedings of the National Academy of Sciences of the United States of America, 89(24), 11832-11836.

32. Shi, X., Gangadharan, B., Brass, L. F., Ruf, W., \& Mueller, B. M. (2004). Protease-activated receptors (PAR1 and PAR2) contribute to tumor cell motility and metastasis. Molecular Cancer Research, 2(7), 395-402.

33. Bromberg, M. E., Bailly, M. A., \& Konigsberg, W. H. (2001). Role of protease-activated receptor 1 in tumor metastasis promoted by tissue factor. Thrombosis and Haemostasis, 86(5), 1210-1214.

34. Bar-Eli, M. (1999). Role of AP-2 in tumor growth and metastasis of human melanoma. Cancer and Metastasis Reviews, 18(3), 377-385.

35. Silini, A., Ghilardi, C., Ardinghi, C., Bernasconi, S., Oliva, P., Carraro, F., et al. (2010). Protease-activated receptor-1 (PAR-1) promotes the motility of human melanomas and is associated to their metastatic phenotype. Clinical \& Experimental Metastasis, 27(1), 43-53.

36. Massi, D., Naldini, A., Ardinghi, C., Carraro, F., Franchi, A., Paglierani, M., et al. (2005). Expression of protease-activated receptors 1 and 2 in melanocytic nevi and malignant melanoma. Human Pathology, 36(6), 676-685.

37. Villares, G. J., Zigler, M., Wang, H., Melnikova, V. O., Wu, H., Friedman, R., et al. (2008). Targeting melanoma growth and metastasis with systemic delivery of liposome-incorporated protease-activated receptor-1 small interfering RNA. Cancer Research, 68(21), 9078-9086.

38. Melnikova, V. O., \& Bar-Eli, M. (2009). Inflammation and melanoma metastasis. Pigment Cell \& Melanoma Research, 22 (3), 257-267.

39. Borsig, L., Wong, R., Feramisco, J., Nadeau, D. R., Varki, N. M., \& Varki, A. (2001). Heparin and cancer revisited: mechanistic connections involving platelets, P-selectin, carcinoma mucins, and tumor metastasis. Proceedings of the National Academy of Sciences of the United States of America, 98(6), 3352-3357.

40. Koop, S., MacDonald, I. C., Luzzi, K., Schmidt, E. E., Morris, V. L., Grattan, M., et al. (1995). Fate of melanoma cells entering the microcirculation: over $80 \%$ survive and extravasate. Cancer Research, 55(12), 2520-2523.

41. Weiss, L. (1994). Inefficiency of metastasis from colorectal carcinomas. Relationship to local therapy for hepatic metastasis. Cancer Treatment and Research, 69, 1-11.

42. Stevenson, J. L., Choi, S. H., \& Varki, A. (2005). Differential metastasis inhibition by clinically relevant levels of heparinscorrelation with selectin inhibition, not antithrombotic activity. Clinical Cancer Research, 11(19 Pt 1), 7003-7011.

43. Koenig, A., Norgard-Sumnicht, K., Linhardt, R., \& Varki, A. (1998). Differential interactions of heparin and heparan sulfate glycosaminoglycans with the selectins. Implications for the use of unfractionated and low molecular weight heparins as therapeutic agents. Journal of Clinical Investigation, 101(4), 877-889.

44. Stevenson, J. L., Varki, A., \& Borsig, L. (2007). Heparin attenuates metastasis mainly due to inhibition of P- and Lselectin, but non-anticoagulant heparins can have additional effects. Thrombosis Research, 120(Suppl 2), S107-S111. 
45. Ramsay, A. G., Marshall, J. F., \& Hart, I. R. (2007). Integrin trafficking and its role in cancer metastasis. Cancer and Metastasis Reviews, 26(3-4), 567-578.

46. Fritzsche, J., Simonis, D., \& Bendas, G. (2008). Melanoma cell adhesion can be blocked by heparin in vitro: suggestion of VLA-4 as a novel target for antimetastatic approaches. Thrombosis and Haemostasis, 100(6), 1166-1175.

47. Zhang, C., Liu, Y., Gao, Y., Shen, J., Zheng, S., Wei, M., et al. (2009). Modified heparins inhibit integrin alpha(Ilb)beta(3) mediated adhesion of melanoma cells to platelets in vitro and in vivo. International Journal of Cancer, 125(9), 2058-2065.

48. Lydolph, M. C., Morgan-Fisher, M., Hoye, A. M., Couchman, J. R., Wewer, U. M., \& Yoneda, A. (2009). Alpha9beta1 integrin in melanoma cells can signal different adhesion states for migration and anchorage. Experimental Cell Research, 315(19), 3312-3324.

49. Witz, I. P. (2008). The selectin-selectin ligand axis in tumor progression. Cancer and Metastasis Reviews, 27(1), 19-30.

50. Fu, J., Naren, A. P., Gao, X., Ahmmed, G. U., \& Malik, A. B. (2005). Protease-activated receptor-1 activation of endothelial cells induces protein kinase Calpha-dependent phosphorylation of syntaxin 4 and Munc18c: Role in signaling p-selectin expression. The Journal of Biological Chemistry, 280(5), 3178-3184.

51. Kansas, G. S. (1996). Selectins and their ligands: current concepts and controversies. Blood, 88(9), 3259-3287.

52. Varki, A. (1997). Selectin ligands: will the real ones please stand up? Journal of Clinical Investigation, 99(2), 158-162. doi:10.1172/ JCI119142.

53. Kim, Y. J., Borsig, L., Varki, N. M., \& Varki, A. (1998). P-selectin deficiency attenuates tumor growth and metastasis. Proceedings of the National Academy of Sciences of the United States of America, 95(16), 9325-9330.

54. Lee, D. Y., Park, K., Kim, S. K., Park, R. W., Kwon, I. C., Kim, S. Y., et al. (2008). Antimetastatic effect of an orally active heparin derivative on experimentally induced metastasis. Clinical Cancer Research, 14(9), 2841-2849.

55. Ludwig, R. J., Schon, M. P., \& Boehncke, W. H. (2007). Pselectin: a common therapeutic target for cardiovascular disorders, inflammation and tumour metastasis. Expert Opinion on Therapeutic Targets, 11(8), 1103-1117.

56. Ludwig, R. J., Alban, S., Bistrian, R., Boehncke, W. H., Kaufmann, R., Henschler, R., et al. (2006). The ability of different forms of heparins to suppress P-selectin function in vitro correlates to their inhibitory capacity on bloodborne metastasis in vivo. Thrombosis and Haemostasis, 95(3), 535-540.

57. Kim, Y. J., Borsig, L., Han, H. L., Varki, N. M., \& Varki, A. (1999). Distinct selectin ligands on colon carcinoma mucins can mediate pathological interactions among platelets, leukocytes, and endothelium. The American Journal of Pathology, 155(2), 461-472.

58. Fuster, M. M., \& Esko, J. D. (2005). The sweet and sour of cancer: glycans as novel therapeutic targets. Nature Reviews. Cancer, 5(7), 526-542.
59. Marshall, B. T., Long, M., Piper, J. W., Yago, T., McEver, R. P., \& Zhu, C. (2003). Direct observation of catch bonds involving celladhesion molecules. Nature, 423(6936), 190-193.

60. Evans, E., Leung, A., Heinrich, V., \& Zhu, C. (2004). Mechanical switching and coupling between two dissociation pathways in a P-selectin adhesion bond. Proceedings of the National Academy of Sciences of the United States of America, 101(31), 1128111286.

61. Ludwig, R. J., Boehme, B., Podda, M., Henschler, R., Jager, E., Tandi, C., et al. (2004). Endothelial P-selectin as a target of heparin action in experimental melanoma lung metastasis. Cancer Research, 64(8), 2743-2750.

62. Hejna, M., Raderer, M., \& Zielinski, C. C. (1999). Inhibition of metastases by anticoagulants. Journal of the National Cancer Institute, 91(1), 22-36.

63. Akl, E. A., van Doormaal, F. F., Barba, M., Kamath, G., Kim, S. Y., Kuipers, S., et al. (2007). Parenteral anticoagulation for prolonging survival in patients with cancer who have no other indication for anticoagulation. Cochrane Database of Systematic Reviews, 3, CD006652.

64. Lebeau, B., Chastang, C., Brechot, J. M., Capron, F., Dautzenberg, B., Delaisements, C., et al. (1994). Subcutaneous heparin treatment increases survival in small cell lung cancer. "Petites Cellules" Group. Cancer, 74(1), 38-45.

65. Zacharski, L. R., Henderson, W. G., Rickles, F. R., Forman, W. B., Cornell, C. J., Jr., Forcier, R. J., et al. (1984). Effect of warfarin anticoagulation on survival in carcinoma of the lung, colon, head and neck, and prostate. Final report of VA Cooperative Study \#75. Cancer, 53(10), 2046-2052.

66. Ornstein, D. L., \& Zacharski, L. R. (2001). Treatment of cancer with anticoagulants: rationale in the treatment of melanoma. International Journal of Hematology, 73(2), 157-161.

67. Ma, Y. Q., \& Geng, J. G. (2000). Heparan sulfate-like proteoglycans mediate adhesion of human malignant melanoma a375 cells to P-selectin under flow. Journal of Immunology, 165(1), 558565.

68. Wei, M., Gao, Y., Tian, M., Li, N., Hao, S., \& Zeng, X. (2005). Selectively desulfated heparin inhibits P-selectin-mediated adhesion of human melanoma cells. Cancer Letters, 229(1), 123-126.

69. Hostettler, N., Naggi, A., Torri, G., Ishai-Michaeli, R., Casu, B., Vlodavsky, I., et al. (2007). P-selectin- and heparanase-dependent antimetastatic activity of non-anticoagulant heparins. The FASEB Journal, 21(13), 3562-3572.

70. Schlesinger, M., Simonis, D., Schmitz, P., Fritzsche, J., \& Bendas, G. (2009). Binding between heparin and the integrin VLA-4. Thrombosis and Haemostasis, 102(5), 816-822.

71. Niers, T. M., Bruggemann, L. W., Klerk, C. P., Muller, F. J., Buckle, T., Reitsma, P. H., et al. (2009). Differential effects of anticoagulants on tumor development of mouse cancer cell lines b16, k1735 and ct26 in lung. Clinical \& Experimental Metastasis, 26(3), 171-178. 